\title{
NUMERICAL SIMULATION OF LANDSCAPE EVOLUTION AND WATER RUN-OFF ON DIGITAL ELEVATION MODELS OBTAINED FROM PLÉIADES
}

\author{
$\mathrm{Morel}^{3}$ \\ 1 : Department of Mathematics, UNC Chapel Hill ; SAMSI, achen@ samsi.info \\ 2: Applied Mathematics Department, UCLA \\ 3: CMLA, ENS de Cachan \\ 4: Centre National d'Etudes Spatiales, Toulouse
}

Alex Chen ${ }^{1}$, Jérôme Darbon ${ }^{2,3}$, Carlo De Franchis ${ }^{3}$, Gabriele Facciolo ${ }^{3}$, Enric Meinhardt ${ }^{3}$, Julien Michel ${ }^{4}$, Jean-Michel

\begin{abstract}
Résumé
Ce document montre comment les principales lois physiques proposées pour l'évolution du paysage peuvent être modélisées par un système de trois équations aux dérivées partielles régissant respectivement le ruissellement, l'érosion du sol, et la sédimentation. Plusieurs expériences numériques sur des modèles altimétriques numériques à haute résolution (MNE) obtenus à partir de paires d'images stéréo du satellite Pléiades illustrent le potentiel de tels modèles pour simuler la structure fine du réseau hydrologique, et pour comprendre la morphologie du paysage et ses causes. Ils permettent aussi de simuler les évolutions plausibles du paysage. Les expériences sur les MNE d'un même site (La Réunion) sont faites à trois résolutions différentes : à la résolution SRTM (90 m), puis à 12 mètres et 4 mètres sur des MNE dérivés de plusieurs paires d'images Pléiades d'un même site. Les expériences montrent que la simulation du ruissellement de l'eau dépend essentiellement de la résolution du DEM. Cela justifie l'utilisation de DEM à haute résolution comme ceux qui peuvent maintenant être produits à partir de paires ou triplets Pléiades.
\end{abstract}

Mots clés : Modèle d'évolution de paysage, équations aux dérivées partielles, réseaux hydrologiques, lois de conservation, loi d'érosion fluviale, érosion à détachement limité et érosion à transport limité, paires stéréoscopiques Pléiades.

\begin{abstract}
This paper illustrates how the main physical laws proposed in landscape evolution (LEMs) can be modeled by a system of three partial differential equations governing water run-off, stream incision, hill slope evolution and sedimentation. Several numerical experiments on high resolution digital elevation models (DEMs) obtained from image stereo pairs of the satellite Pléiades illustrate its potential to simulate the fine structure of the river network, and to understand the landscape morphology and its causes. They also permit to simulate plausible evolutions. The experiments on DEMs of the same site (La Réunion) are made at three different resolutions : the SRTM resolution $(90 \mathrm{~m})$, and then $12 \mathrm{~m}$ and $4 \mathrm{~m}$ on DEMs derived from several Pléiades pairs of the same site. The experiments show that the water run-off simulation critically depends on the DEM resolution. This justifies the use of high resolution DEMs like those that can now be produced from Pléiades pairs or triplets.
\end{abstract}

Keywords : Landscape evolution model, partial differential equations, river networks, conservation laws, stream incision law, detachment-limited and transport-limited erosion, Pléiades stereopairs.

\section{Introduction}

Among other goals geomorphological research attempts to model and explain the evolution of landscape morphology under the conjugated effects of erosion, sedimentation, chemical weathering, creep, tectonic motions, etc. Erosion (runoff) is the removal of sediment from the land surface by a fluid agent such as water or air, while sedimentation is the converse process, in which sediment from the fluid mixture settles onto the land surface. During storm events, rainfall increases the erosion and sedimentation activity. By estimating the amount of erosion and sedimentation, an estimate for the dynamics of the landscape can be obtained. This effect can be complemented by a terrain smoothing effect called creep, whose description and causes are multiple (water splash, chemical and thermal weathering, gravitational flow of soft soil). All of these effects and others can be modeled by a landscape evolution model (LEM), summarized in a few partial differential equations. The simulation of a landscape evolution model requires a thorough knowledge of the Earth morphology, at the highest possible resolution. To that effect, increasingly accurate digital elevation models (DEMs) are indispensable and must cover large pieces of the landscape, including whole basins, islands or continents. Numerically simulated DEM evolution and its comparison with the observed landscape morphologies will eventually permit the estimation of the main model parameters for each landscape.

Landscape evolution modeling based on photographs goes 

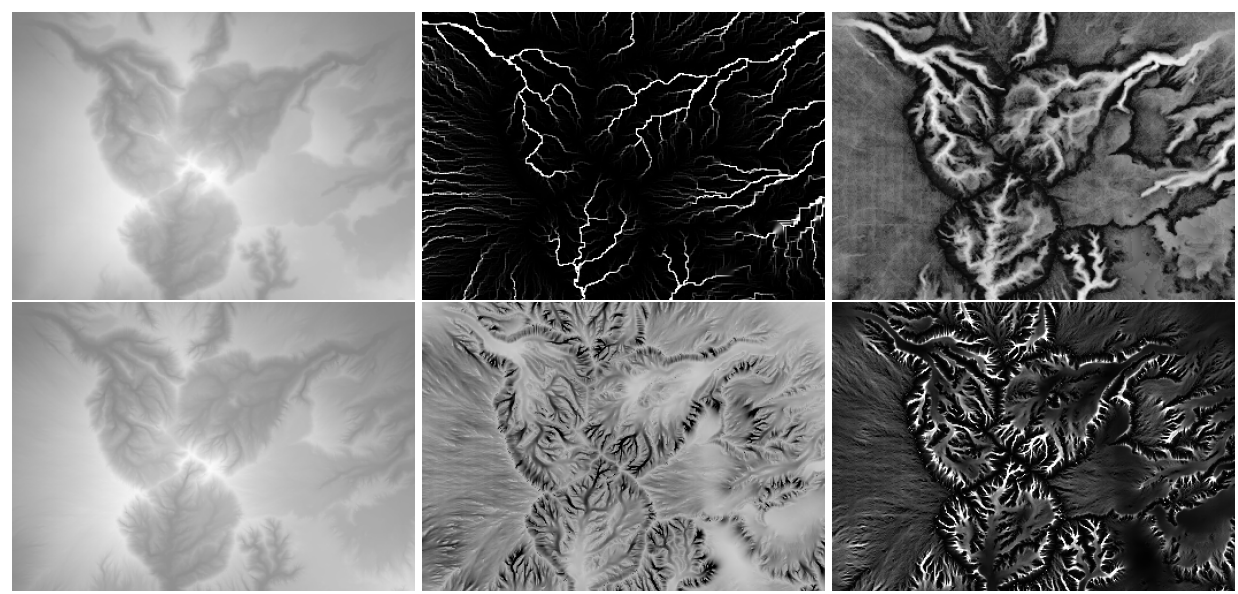

FIGURE 1 : This simulation, on a 90 meter resolution SRTM model of Piton des Neiges, La Réunion, shows all state variables that are being displayed in a numerical LEM. Top left : initial DEM. Top middle : river network obtained by the classic method which identifies it with the drainage basin area. Top right : the steady state value under uniform rain of the water elevation $\theta(x, y)$ when water runs on the landscape without any erosion.

Bottom row : evolution for parameters rain $r=10$, erosion $\epsilon=0.1$, creep $c=0.1$, after removal by erosion of $5 \%$ of the landscape. Bottom left : final landscape. Bottom middle : last evolution of the landscape (landscape derivative) just before stopping, where black denotes large values and white small values. Bottom right : map $\lambda(x, y)$ of the sediment load in water at the beginning of the erosion process. See section 2 for more explanations on the parameters.

back to Gilbert and Dutton (1877). The observation of real landscapes and photographs and clever qualitative reasoning led Gilbert (1909) to establish a mix of quantitative and qualitative principles governing all landscapes. The first mathematical explanation of the convexity of hilltops, ascribed to creep, is attributable to Davis (1892). Ever since the analysis of Gilbert, landscape evolution models have involved mainly two competing factors : on the higher slopes, where water currents are weak and dispersive, soil creep dominates and the profiles are convex. On lower slopes, water flow concentrates and profiles become concave leading to the formation of valleys. Gilbert proved that creep was dominant over other factors, such as wind and rain beat.

In this paper we show experiments on high resolution Pléiades DEMs. We base our numerical experiments on a recent LEM derived through a simplification of a rich list of complex numerical LEMs and software proposed in the past twenty years. The prominent ones are LEGS (Paik, 2012), SIGNUM (Refice et al., 2012), SIBERIA, CAESAR (Hancock et al., 2011), CASCADE (Braun and Sambridge, 1997), DELIM (Howard, 1994), ZSCAPE, LANDSAP (Luo, 2001), GOLEM (Tucker and Slingerland, 1994), APERO (Carretier and Lucazeau, 2005), EROS (Crave and Davy, 2001), and Fastscape (Braun and Willett, 2012). The model which we follow is introduced in (Chen et al., 2014a) and precised in (Chen et al., 2014b), where it is demonstrated that most features of previous numerical LEMs can be summarized in a system of three partial differential equations governing water runoff, erosion and sedimentation. We shall recall these equations in the next section. The objective of a generic LEM models is to identify the parameters responsible for the morphology of a landscape. The aforementioned numerical LEMs and software contain dozens and sometimes hundreds of landscape specific parameters. Yet an exhaustive numerical exploration cannot identify more than four or five independent parameters. The LEM which we shall

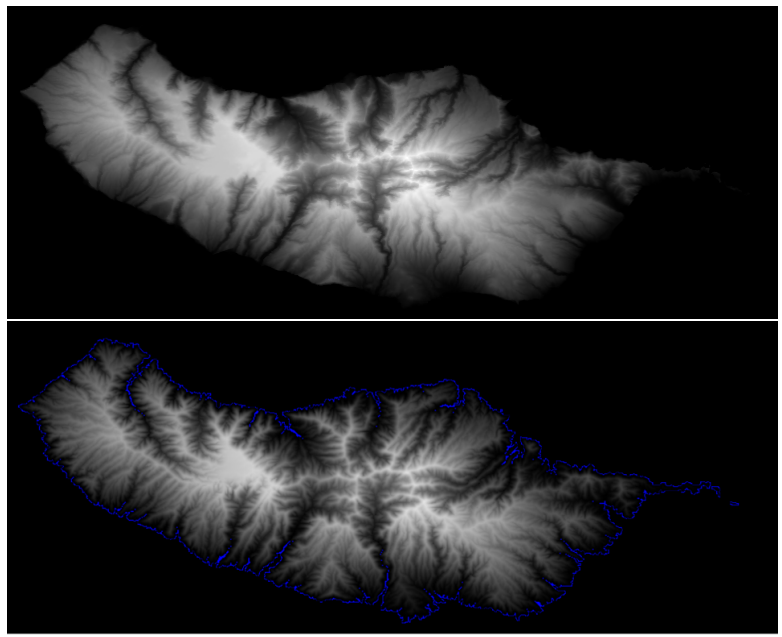

FIGURE 2 : The simulation of the correct equations with the right few parameters should maintain a stable morphology (on stable landscapes!). The challenge is to identify automatically the parameters for each (stable) landscape. Here : Madeira, percentage removed : 40\%.

use involves only four parameters. The numerical LEM yields for each initial DEM $z(x, y, 0)$ and each set of parameters an evolved DEM $z(x, y, t)$ under the conjugate effects of erosion and sedimentation. It also yields the final maps of the water height $\theta(x, y, t)$ and of the sediment load $\lambda(x, y, t)$ for each given steady rain rate $r$. Figure 1 shows such a simulation on an SRTM DEM of the central peak of La Réunion, the Piton des Neiges. It was processed by the test system of three equations (2.2)-(2.4) described in section 2.

The validity of a such a numerical program is sustainable if one can show that a landscape evolution model indeed gives a correct account of landscape evolution on various geological time ranges. Yet, this would require the observation of DEMs 
on geological time scales incommensurable with human time scales. Fortunately, we found that a simple (but costly) numerical procedure can deliver a sound estimate of the parameters of a landscape. The (currently manual) procedure explores potential and reasonable parameter sets, and evolves for each one the landscape until a fixed percentage of the landscape has been scraped and transported by the erosion-sedimentation process. If the landscape morphology is stable and if the right parameters have been found, one can expect that the evolved landscape maintains its morphology (same valleys, similar slopes, etc.). This manual procedure should evolve into a systematic exploration on a large set of (stable) landscapes. This will require an adequate criterion to decide if a morphology is stable under the simulated weathering process. A tentative norm for such morphology stability measurements could be the Sobolev semi-norm $\int|\nabla(z(x, y, t)-z(x, y, 0))| d x d y$ where $z(x, y, t)$ is the DEM elevation at time $t$ and $t=0$ denotes the observed DEM.

We already succeeded in some examples to find manually the right parameter set on the Madeira island, as illustrated in Figure 2. On a Madeira's SRTM DEM, we tested our three equations model with many different four-parameter sets, until we found one for which the landscape morphology was stable even after $40 \%$ of the emerged ground had been eroded and transported away. A visual exploration shows a completely stable morphology after this drastic evolution.

Yet our first numerical experiments on Pléiades data turn out to have been applied on very young unstable volcanic landscape, the La Réunion island. For such an instable landscape, where basins are still in formation, we can nevertheless find sets of parameters for which the existing basins seem to extend in a natural way. One can in that way envisage various evolutions of this landscape after the volcanic activity gets extinct. Figure 3 displays such plausible evolutions toward a stable landscape, mainly depending on the creep/rain/erosion rate balance.

\section{The main landscape evolution equations}

The numerical LEM used here was introduced in Chen et al. (2014a) and extended in Chen et al. (2014b). In the forthcoming equations, lowercase letters denote functions of the landscape depending on two geographic coordinates $(x, y)$ and on time $t$. The function $\theta(x, y, t)$ denotes the water height at $(x, y)$ and time $t$, and similarly $z(x, y, t)$ is the bedrock surface elevation, $\theta(x, y, t)$ the water height. For a sake of simplicity, we shall in general omit the triplet $(x, y, t)$ in the equations. We denote by $\mathbf{z}=z+\theta$ the landscape altitude (land surface elevation plus water), $|\nabla(z+\theta)|$ the landscape slope, $\lambda$ the sediemnt load in water, so that $\frac{\lambda}{\theta}$ is the sediment density in water. Finally $\mathbf{v}$ is the water velocity. (All of these state variables depend on $(x, y, t).) \nabla \phi$ denotes the gradient of a scalar variable $\phi(x, y), \Delta \phi$ its Laplacian, and $\nabla \cdot \mathbf{v}$ the divergence of a vector field $\mathbf{v}(x, y)$. There are also landscape specific parameters in the equations, that for simplicity we assume constant in time and space on each landscape. These parameters, that can be tuned to find the right set, are $c$ the creep rate, $\epsilon$ the erosion rate, $r$ the rain rate, $s$ the sedimentation rate and $m$ the erosion exponent. Since $m=\frac{1}{2}$ was fixed, the numerical model actually depends on four parameters.

We picked the simplest possible version for the generalized Gauckler-Manning, Saint-Venant law (Gauckler, 1867) so that the water velocity is simply the negative of the slope,

$$
\mathbf{v}=-\nabla(z+\theta)
$$

There is no simpler way to express the common sense observation that water runs downs the slope. The system used in all experiments governing the evolution of the landscape elevation $z$, the water depth $\theta$ and the sediment load $\lambda$ in water is composed of three equations :

1. the water conservation and transport law

$$
\frac{\partial \theta}{\partial t}=\nabla \cdot(\theta \nabla(z+\theta))+r
$$

2. the landscape evolution equation with creep, incision law, sediment deposition

$$
\frac{\partial z}{\partial t}=c \Delta z-\epsilon \theta^{m}|\nabla(z+\theta)|^{2 m}+s \frac{\lambda}{\theta}
$$

and the conservation of sediment law,

$$
\frac{\partial \lambda}{\partial t}=\nabla \cdot(\lambda \nabla(z+\theta))+\epsilon \theta^{m}|\nabla(z+\theta)|^{2 m}-s \frac{\lambda}{\theta} .
$$

Simulating this system still depends on five parameters, the erosion exponent $m$, the amount of rain $r$, the creep rate $c$, the sedimentation rate $s$, and the erosion speed $\epsilon$. A stopping time must also be specified and we decided to fix it as the percentage of DEM erosion, namely the ratio $p$ of the average eroded elevation in the DEM to the initial average elevation above its minimal level. We explored typical values of $5 \%$ to $30 \%$ that make the evolution visually conspicuous. Since $m=\frac{1}{2}$ the actual number of parameters remains four.

The first equation (2.2) in this three equation system is the simplest possible water run-off formulation, which can be viewed as a minimal version of Saint-Venant shallow water equations. In words, it simply states that water runs off at each point $(x, y)$ in the direction opposite to its elevation gradient $\nabla[z+\theta](x, y)$. The source term $r$ expresses that rain is falling at constant rate all over the landscape. Of course nothing prevents using a space or time variable $r(x, y, t)$ if such rainfall data rates are available. The second equation (2.3) contains all of the water-ground interactions. The first one is Gilbert's creep evolution

$$
\frac{\partial z}{\partial t}=c \Delta z
$$

by which a landscape tends to get smooth and round by a diffusion process. The constant $c$ reflects a diffusion speed depending on soil conditions and on the previously mentioned various perturbing factors (rain splash, wind, chemical weathering, ...). Such a creep term is found, among others, in Fernandes and Dietrich (1997), the GOLEM numerical simulation system (Tucker and Slingerland, 1994) Tucker and Slinger- 
land (1994), Moglen et al. (1998), Simpson and Schlunegger (2003), Culling (1960), Willgoose et al. (1991).

The second term $-\epsilon \theta^{m}|\nabla(z+\theta)|^{2 m}$ in (2.3) expresses the stream incision law (Niemann et al., 2001), (Dietrich and Perron, 2006). It states that the erosion rate in a channel increases with the flux of water in the channel and with the local gradient. The preferred exponent in many models is $m=\frac{1}{2}$. The third term in the second equation (2.3) $-s \frac{\lambda}{\theta}$ is Exner's sedimentation law by which the sedimentation rate is proportional to the density of sediment $\frac{\lambda}{\theta}$ in water.

To summarize, the second equation expresses that the elevation $z(x, y, t)$ evolves under the conjugate actions of creep, erosion and sedimentation. The third equation (2.4) simply expresses the conservation and transport law of the sediment $\lambda(x, y)$ carried by the water. The first term is the run off term, strictly analogous to the one present in (2.2) for water run off, as sediment is carried by water at the same horizontal velocity. The second and third terms are the opposite of the terms present in (2.3). Indeed, the terrain scraped by erosion becomes transported sediment, and can sediment to become terrain again.

The simulations of Figure 3 illustrates the variety of morphologies that can be reached from an initial DEM by varying the parameters of the two-equation model, namely equations (2.2-2.3) (in that way, no sedimentation occurs, which makes sense in the sloppy La Réunion). Some of the evolutions maintain a qualitative landscape morphology similar to the original, while others create new basins and rivers and evolve the DEM toward a different morphology. For example the second result and the fourth are obtained by fixing the same erosion percentage, $20 \%$. But the second is still very similar to the original, showing a slow morphological evolution, while the fourth has created or expanded basins, as the landscape evolves to a mature form. In the middle of the last row, the exponent $m=0.6$ in the incision law has been changed. from $m=0.5$ in the other experiments. Observe that this modification is enough to modify valley spacing on the left slope. It seems sound to deduce from this variety of result that, only with four control parameters, a large variety of landscapes morphologies can be modeled by a three-equation model.

\section{La Réunion at Pléiades resolution}

This section presents two experiments for a comparative study of numerical LEM simulation on the same landscape, La Réunion, at three very different resolutions. The results show a coherence of the aspect of the evolved landscapes at all resolutions. But they also show that the numerical landscape evolution leads to the emergence of a very fine resolution network. So the better the initial resolution, the better the prediction. We have shown the results of LEM simulations on an SRTM 90m La Réunion DEM in Figure 3. Figures 4 and 5 show analogue results at much higher resolutions on DEMs obtained from Pléiades stereo pairs by applying a stereo reconstruction algorithm yielding respectively DEMs at 12 meters/pixel and $3 \mathrm{~m} /$ pixel using the method sketched in de Franchis et al. (2014). In Figure 4, we display first one image of a stereo pair of Piton des Neiges, La Réunion. This image at circa 12 meters/pixel is obtained by numerical zoom out from Pléiades (CNES 2014, Distribution Astrium Services). With this zoom out the image stereo pair has become virtually noiseless. Thus our automatic DEM reconstruction chain S2P de Franchis et al. (2014) yields a fairly dense reconstruction. Nevertheless, interpolation remains necessary to remove holes left by the stereomatching in dark regions (not lit directly by the sun) and in zones with very fine texture, which both correspond to a low SNR, making block matching fail. The next image shows a plausible DEM evolution, which is stopped when $10 \%$ of the terrain has been removed by erosion. The parameters in the equation are rain $r=1$, erosion $\epsilon r=1$, creep $c=16$, sedimentation $s=1$; The images of the last row of the figure show the water network at the end of the evolution $\theta(x, y)$ and the sediment density contained in water $\lambda(x, y)$, revealing still better the fine structure of the hydrological network, as sediment has high concentration in the fine network. This experiment illustrates the sensitivity of numerical landscape evolution to the initial resolution; clearly the simulated network tends to increase the DEM resolution by recreating a fine channel network that was missing in the original DEM. This suggests that much will be gained by increasing still the resolution, as it is by now possible with Pléiades Earth stereo imaging. The nominal resolution of Pléiades being $0.7 \mathrm{~m}$, nothing prevents from simulating landscape evolution at this resolution. This makes sense, because water runoff is very shallow except in big rivers, and therefore definitely affected by landscape roughness at the very scale of Pléiades observation. We shall be contented here to compare our previous landscape evolution at $12 \mathrm{~m}$ to the result of the same LEM applied this time to a circa 4 meter resolution stereo pair (Figure 5). The second stereo pair of Piton des Neiges, La Réunion, DEM was obtained by zoom out from the same original stereo Pléiades pair (CNES 2014, Distribution Astrium Services). The DEM therefore gets a three times finer resolution and was again interpolated to remove the holes where stereo matching failed. Again, a plausible evolution toward a stable landscape is shown, after $10 \%$ of the terrain has been removed by erosion. The parameters in the equation are rain $r=1$, erosion $\epsilon r=1$, creep $c=32$, sedimentation $s=1$. We display the landscape evolution results in the same format as in Figure 4 : water network at the end of the evolution $\theta(x, y)$; sediment contained in water $\lambda(x, y)$, revealing the still finer structure of the hydrological network. While both networks look compatible, it is clear that the landscape evolution at a finer scale is different. If follows from this observation, as we already anticipated, that applying LEMs at 50 centimeters scale is probably necessary to obtain a realistic simulation and get to the critical scales at stake in landscape evolution. This without any doubt requires a huge but feasible numerical machinery, and it requires stereo pair at a Pléiades resolution, or finer.

\section{Références}

Braun, J., Sambridge, M., 1997. Modelling landscape evolution on geological time scales : a new method based on irregular spatial discretization. Basin Res. 9, 27-52. 

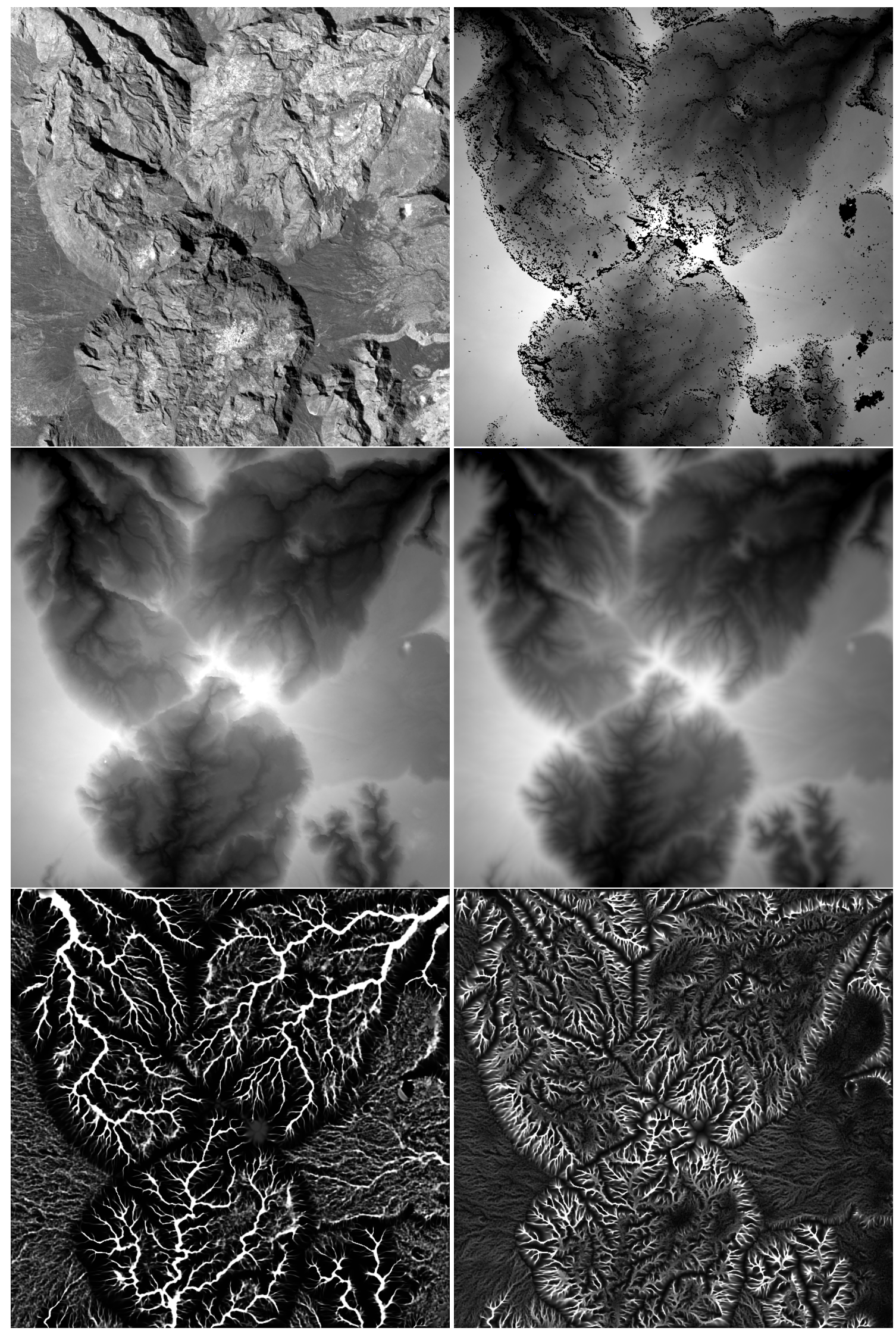

FIgURE 4 : From top left to bottom right : Piton des Neiges, La Réunion, image at circa 12 meters/pixel by numerical zoom out, obtained from Pléiades (CNES 2014, Distribution Astrium Services); DEM of the same; same DEM, interpolated to remove holes left by the stereomatching in dark regions; a plausible evolution, where $10 \%$ of the terrain has been removed by erosion. The parameters in the equation are rain $r=1$, erosion $\epsilon r=1$, creep $c=16$, sedimentation $s=1$; water network at the end of the evolution $\theta(x, y)$; sediment contained in water $\lambda(x, y)$, revealing the fine structure of the hydrological network. 


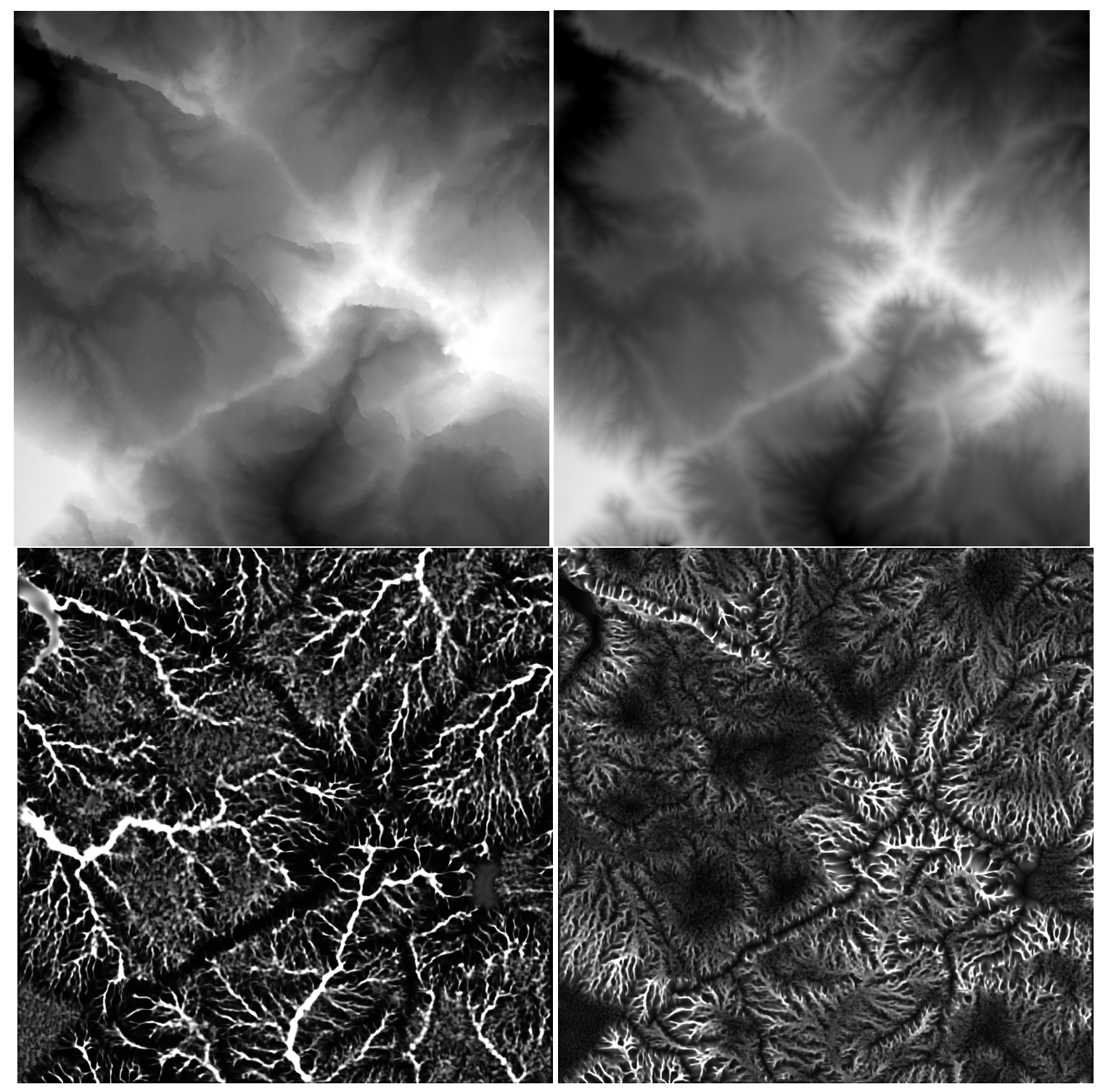

FIGURE 5 : From top left to bottom right : Piton des Neiges, La Réunion, DEM at circa 4 meters/pixel obtained from Pléiades (CNES 2014, Distribution Astrium Services) ; a plausible evolution toward a stable landscape, after $10 \%$ of the terrain has been removed by erosion. The parameters in the equation are rain $r=1$, erosion $\epsilon r=1$, creep $c=32$, sedimentation $s=1$; water network at the end of the evolution $\theta(x, y)$; sediment contained in water $\lambda(x, y)$, revealing the fine structure of the hydrological network. 

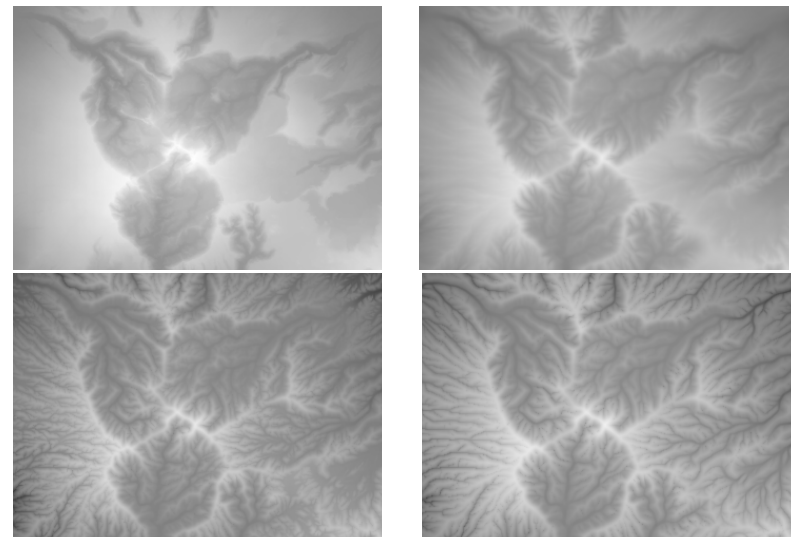

FIGURE 3 : This experiment illustrates the variety of morphologies that can be reached from an initial DEM by varying the parameters of a three-equation model. From top to bottom and from left to right, we have the initial landscape and then the evolved landscape for $(r, \epsilon, c, p)=(5,1,10,20),(1,1,2,20),(1,1,0.5,30)$ with $m=0.6$. Notice how some of the evolutions maintain a similar landscape, while others create new basins and rivers and evolve it toward a different morphology. For example the second result and the third are obtained with the same final amount of scrapped land, $20 \%$. But the first is still very similar to the original, showing a slow morphological evolution, while the second has created or expanded basins, as the landscape evolves to a mature form. In the last experiment, the exponent $m=0.6$ has been changed. In all other experiments it is $m=0.5$. Observe that this modification seems to modify valley spacing on the left slope. Data : SRTM La Réunion, Piton des Neiges. See section 2 for more detail on the equations and parameters.

Braun, J., Willett, S. D., 2012. A very efficient $O(n)$, implicit and parallel method to solve the stream power equation governing fluvial incision and landscape evolution. Geomorphology, 170-179.

Carretier, S., Lucazeau, F., 2005. How does alluvial sedimentation at range fronts modify the erosional dynamics of mountain catchments ? Basin Res. 17 (3), 361-381.

Chen, A., Darbon, J., Buttazzo, G., Santambrogio, F., Morel, J.-M., 2014a. On the equations of landscape formation. Interfaces and Free Boundaries 16 (1), 105-136.

Chen, A., Darbon, J., Morel, J.-M., 2014b. Landscape evolution models : A review of their fundamental equations. Geomorphology 219, 68-86.

Crave, A., Davy, P., 2001. A stochastic "precipiton" model for simulating erosion/sedimentation dynamics. Comput. Geosci. 27 (7), 815827.

Culling, W. E. H., 1960. Analytical theory of erosion. J. Geol. 68 (3), 336-344.

Davis, W. M., 1892. The convex profile of bad-land divides. Science (508), 245.

de Franchis, C., Meinhardt-Llopis, E., Michel, J., Morel, J.-M., Facciolo, G., 2014. Automatic digital surface model generation from pléiades stereo images. Revue Française de Photogrammétrie et de Télédétection This volume.

Dietrich, W. E., Perron, J. T., 2006. The search for a topographic signature of life. Nature 439 (7075), 411-418.

Fernandes, N. F., Dietrich, W. E., 1997. Hillslope evolution by diffusive processes : The timescale for equilibrium adjustments. Water Resour. Res. 33 (6), 1307-1318.

Gauckler, P., 1867. Etudes Théoriques et Pratiques sur l'Ecoulement et le Mouvement des Eaux. C. R. Acad. Sci. Paris 64, 818-822.

Gilbert, G. K., 1909. The convexity of hilltops. J. Geol. 17 (4), 344350.
Gilbert, G. K., Dutton, C. E., 1877. Report on the Geology of the Henry Mountains. Govt. print. off.

Hancock, G. R., Coulthard, T. J., Martinez, C., Kalma, J. D., 2011 An evaluation of landscape evolution models to simulate decadal and centennial scale soil erosion in grassland catchments. J. Hydrol. 398 (3), 171-183.

Howard, A. D., 1994. A detachment-limited model of drainage basin evolution. Water Resour. Res. 30 (7), 2261-2285.

Luo, W., 2001. LANDSAP : a coupled surface and subsurface cellular automata model for landform simulation. Comput. Geosci. 27 (3), 363-367.

Moglen, G. E., Eltahir, E. A. B., Bras, R. L., 1998. On the sensitivity of drainage density to climate change. Water Resour. Res. 34 (4), 855-862.

Niemann, J. D., Gasparini, N. M., Tucker, G. E., Bras, R. L., 2001. A quantitative evaluation of Playfair's law and its use in testing long-term stream erosion models. Earth Surf. Proc. Land. 26, 1317 1332.

Paik, K., 2012. Simulation of landscape evolution using a global flow path search method. Environ. Modell. Softw. 33, 35-47.

Refice, A., Giachetta, E., Capolongo, D., 2012. SIGNUM : A matlab, TIN-based landscape evolution model. Comput. Geosci. 45, 293 303.

Simpson, G., Schlunegger, F., 2003. Topographic evolution and morphology of surfaces evolving in response to coupled fluvial and hil1slope sediment transport. J. Geophys. Res. 108 (B6), 2300.

Tucker, G. E., Slingerland, R. L., 1994. Erosional dynamics, flexural isostasy, and long-lived escarpments : A numerical modeling study. J. Geophys. Res. 99 (B6), 12229-12243.

Willgoose, G., Bras, R. L., Rodriguez-Iturbe, I., 1991. A coupled channel network growth and hillslope evolution model : 2. Nondimensionalization and applications. Water Resour. Res. 27 (7), 16851696. 